Monastyrska N. Ya. Quatitative morphological analysis of the venous bed of the common bile duct in postresection portal hypertension. Journal of Education, Health and Sport. 2020;10(10): 358-363. eISSN 2391-8306. DOI http://dx.doi.org/10.12775/JEHS.2020.10.10.034

https://apcz.umk.pl/czasopisma/index.php/JEHS/article/view/JEHS.2020.10.10.034

https://zenodo.org/record/4536041

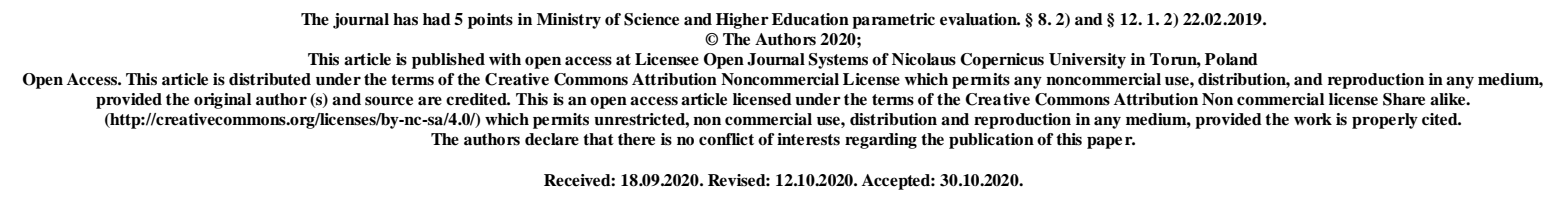

UDK [616.36 - 089.87 - 06:616-091] - 092.9

\title{
QUANTITATIVE MORPHOLOGICAL ANALYSIS OF THE VENOUS BED OF THE COMMON BILE DUCT IN POSTRESECTION PORTAL HYPERTENSION
}

\author{
N. Ya. Monastyrska
}

\section{Ivan Horbachevsky Ternopil National Medical University of the Ministry of Health of Ukraine}

\begin{abstract}
Introduction. Removal of the left and right lateral lobes of the liver in white rats leads to postresection portal hypertension, which is characterized by dilation and plethora of the hepatic portal vein, mesenteric veins, esophageal and gastric veins, veins of the anterior abdominal wall, splenomegaly, ascites.

Objective of the research: to study the features of structural reorganization of the venous bed of the common bile duct in postresection portal hypertension morphometrically.

Materials of the research and their discussion. The venous bed of the common bile duct was studied by morphometric methods in 32 laboratory white male rats, which were divided into 2 groups: 1-st group included 15 intact animals, 2-nd - 17 rats with postresection portal hypertension, which was modeled by removal of the left and right hepatic lobes. One month after the start of the experiment, rats were euthanized by bloodletting under conditions of thiopental anesthesia. Histological micropreparations were made from the common bile duct, on which the venous bed was mophometrically studied, the outer and inner diameters of veins, wall thickness, height of endotheliocytes, diameter of their nuclei, nuclear-cytoplasmic
\end{abstract}


ratios in these cells, relative volume of damaged endothelial cells were measured. Quantitative indicators were processed statistically.

Results of the research and their discussion. Morphometrically it was found that in postresection portal hypertension the outer and inner diameters of veins of the common bile duct markedly increased, their wall is thinned, the height of endothelial cells, the diameters of their nuclei decreased, the nuclear-cytoplasmic ratios in endotheliocytes were disturbed, the relative volume of damaged endothelial cells increased.

Conclusions. Resection of the left and right lateral lobes of the liver in white rats leads to postresection portal hypertension and pronounced remodeling of the venous bed of the common bile duct, which was characterized by increase of outer and inner diameters of veins, thinning of their wall, decrease of height of endotheliocytes and diameters of their nuclei, violation of nuclear-cytoplasmic ratios in endothelial cells, increase of relative volume of damaged endothelial cells.

Key words: postresection portal hypertension; veins of the common bile duct; morphometry.

Introduction. Liver resection is often performed in modern surgical clinics in benign and malignant tumors, metastases, liver injuries, alveolar echinococcosis, cholangiocarcinomas, liver transplantation $[3,8]$.

Removal of large part of the liver may be complicated by postresection portal hypertension, which leads to severe complications: bleeding from varicose veins of the esophagus and stomach, rectum, ascites, splenomegaly, secondary hypersplenism, parenchymal jaundice, hepatic and multiorgan failure, portosystemic encephalopathy $[4,9$, 10]. It should be noted that the remodeling (structural reorganization) of the venous vascular bed of the common bile duct in postresection portal hypertension remains poorly understood.

Modern researchers claim that adequate and accurate information about various physiological and pathological processes occurring in organs and systems of the body can be obtained using morphometry, which is now widely used by morphologists and most fully objectifies the results of morphological studies, which allows deeper study, adequate and accurate interpret them $[1,9]$.

Objective of the research: to study the features of structural reorganization of the venous bed of the common bile duct in postresection portal hypertension morphometrically.

Materials of the research and their discussion. The venous bed of the common bile duct was studied by morphometric methods in 32 laboratory white male rats, which were 
divided into 2 groups: 1-st group included 15 intact animals, 2-nd - 17 rats with postresection portal hypertension. The latter was modeled by removing the left and right lateral lobes of the liver (58.1\% of its parenchyma) [9]. One month after the start of the experiment, rats were euthanized by bloodletting under conditions of thiopental anesthesia. Histological micropreparations were made from the common bile duct $[2,6]$, on which the outer (DO) and inner diameters of veins (DI), the wall thickness (WT), the height of endotheliocytes (HE), the diameter of their nuclei (DNE), the nuclear-cytoplasmic ratios in these cells (NCRE), the relative volume of damaged endothelial cells (RVDE) were measured. Morphometric measurements were perfomed using the program "Video-Test-5.0". Quantitative indicators were processed statistically [1]. Processing of results was pefomed in the department of system statistical researches of Ivan Horbachevsky Ternopil National Medical University of the Ministry of Health of Ukraine in the software package STATISTICA. The difference between the comparative values was determined by the Mann-Whitney and Student test $[1,5]$.

Results of the research and their discussion. Resection of the left and right lateral lobes of the liver in white rats leads to postresection portal hypertension, which was confirmed by plethora and dilation of the hepatic portal vein, mesenteric veins, esophageal and gastric veins, veins of the anterior abdominal wall, ascites, splenomegaly. Morphometric parameters obtained as a result of the study are presented in the table. Analysis of the data in this table revealed that postresection portal hypertension led to pronounced remodeling of the venous bed of the common bile duct. Thus, the outer diameter of the veins of the studied organ in the simulated experimental conditions increased statistically significantly $(\mathrm{p}<0.001)$ by $19.5 \%$, inner - by $38.5 \%(\mathrm{p}<0.001)$ compared with similar control indicators. The wall thickness of the veins of the common bile duct with a pronounced statistically significant difference $(\mathrm{p}<0.001)$ decreased by $18.6 \%$.

The height of endotheliocytes of the veins of the common bile duct in postresection portal hypertension decreased from $(6.30 \pm 0.09) \mu \mathrm{m}$ to $(5.70 \pm 0.05) \mu \mathrm{m}$, that is by $9.5 \%$ $(\mathrm{p}<0.001)$, diameter of their nuclei - by $40.5 \%$ ( $<<0.001)$. Uneven, disproportionate changes of the morphometric parameters of endothelial cells and their nuclei led to disturbances in these cells of nuclear-cytoplasmic ratios, which were changed by $43.1 \%(\mathrm{p}<0.001)$. Some researchers affirm that pronounced changes of the nuclear-cytoplasmic ratios in cells indicate about the violation of cellular structural homeostasis [7]. 
Table - Morphometric parameters of the venous bed of the common bile duct of experimental animals $(\mathrm{M} \pm \mathrm{m})$

\begin{tabular}{|l|c|c|}
\hline \multirow{2}{*}{ Показник } & \multicolumn{2}{|c|}{ Group of animals } \\
\cline { 2 - 3 } & 1 -st & 5 -th \\
\hline $\mathrm{DO}, \mu \mathrm{m}$ & $38,75 \pm 0,42$ & $46,30 \pm 0,48^{* * *}$ \\
\hline $\mathrm{DI}, \mu \mathrm{m}$ & $25,85 \pm 0,33$ & $35,80 \pm 0,36^{* * *}$ \\
\hline $\mathrm{WT}, \mu \mathrm{m}$ & $12,90 \pm 0,18$ & $10,50 \pm 0,12^{* * *}$ \\
\hline $\mathrm{HE}, \mu \mathrm{m}$ & $6,30 \pm 0,09$ & $5,70 \pm 0,05^{* * *}$ \\
\hline $\mathrm{DNE}, \mu \mathrm{m}$ & $4,54 \pm 0,04$ & $2,70 \pm 0,03^{* * *}$ \\
\hline $\mathrm{NCRE}$ & $0,520 \pm 0,006$ & $0,224 \pm 0,003^{* * *}$ \\
\hline RVDE, \% & $2,30 \pm 0,03$ & $36,30 \pm 0,42^{* * *}$ \\
\hline \multicolumn{2}{|c|}{ Note. $* * *-\mathrm{p}<0.001$ compared with the 1-st group. } \\
\hline
\end{tabular}

The relative volume of damaged endothelial cells of the venous bed of the common bile duct in laboratory adult white rats of the control group was $(2,30 \pm 0,03) \%$, in experimental animals with postresection portal hypertension - $(36,30 \pm 0,42) \%$. The presented morphometric parameters with a high degree of statistically significant difference $(p<0.001)$ differed from each other. The last quantitative morphological indicator exceeded the previous one in 15.8 times $[1,2]$.

The endothelial cells play an important role in the regulation of blood circulation, synthesize various biologically active substances which are necessary for the regulation of vital processes in the body [7].

Damage of a significant number of vascular endothelial cells in postresection portal hypertension leads to their dysfunction: blockade of NO-synthase, decreased NO synthesis, activation of its degradation processes, increased synthesis of vasoconstrictors (endothelin, angiotensin-II, thromboxane A2, prostaglandin $\mathrm{H} 2$ ) which is complicated by narrowing of arterial vessels, significantly impairs the blood supply of the studied organs and exacerbates hypoxia [7].

The latter and venous hyperemia lead to a cascade of pathological reactions: increase of proinflammatory cytokines, inflammatory mediators, highly active free radicals, which adversely affects the intercellular structures, cell membranes and vascular wall. Under these conditions, the basal vascular membrane, endothelial cells and interndothelial contacts are damaged. Under these conditions, the concentration of endothelin-1 in the blood is increased, which intensifies the vasoconstriction of arteries by activation of $\mathrm{Ca} 2+-$-channels, proliferation of endothelial cells, smooth myocytes and fibroblasts in the vascular wall, stimulates the apoptosis, causes the expression of adhesive molecules. As a result of violation of 
intercellular contacts, endothelial cells, the permeability of the vascular wall, endothelial cells are increased, their barrier function is deteriorated.

Light-optically there was a dilation and plethora of mostly venous vessels in the membranes of the studied organ in postresection portal hypertension. The venous microvessels of the hemomicrocirculatory bed are unevenly expanded, tortuous, plethoric, sometimes varicosely dilated with numerous sacculations. Stasis, thrombosis, diapedetic hemorrhages, plasmorrhagia of the wall of venous vessels and paravasal structures were found in these vessels. There was swelling, foci with a decrease of the density of microvessels due to their reduction, avascular zones in the membranes of the common bile duct. The places of reduction of the microvessels in micropreparations were visualized as thick-walled fibrous bands, sometimes with signs of hyalinosis. The endothelial cells of the microvessels and muscular cells, stromal structures with phenomena of edema, dystrophically and necrobiotically altered. The foci of the infiltration and sclerosis were observed in the stroma of the studied organ. Postresection portal hypertension leads to a pronounced remodeling of the venous vessels of the common bile duct, violation of the venous drainage from the studied organ, venous plethora, hypoxia, trophic disorders, dystrophic, necrobiotic changes of endotheliocytes of the vessels, smooth myocytes, stromal structures, infiltration and sclerosis.

Conclusions. Resection of the left and right lateral lobes of the liver in white rats leads to postresection portal hypertension and pronounced remodeling of the venous bed of the common bile duct, which was characterized by increase of outer and inner diameters of veins, thinning of their wall, decrease of height of endotheliocytes and diameters of their nuclei, violation of nuclear-cytoplasmic ratios in endothelial cells, increase of relative volume of damaged endothelial cells.

\section{References}

1. Avtandilov GG. Basis of quantitative pathological anatomy. Moscow: Medicine. 2002. 240 p.

2. Bagriy MM, Dibrova VA, Popadynets OG. Methods of morphological research. Vinnitsa: New book. 2016. 328 p.

3. Dronov OI, Zemskov SV, Bakunets YuP. Surgical treatment of focal hepatic affection: analysis of the results and perspectives. Clinical surgery. 2016. № 1. P. 28-31.

4. Dzygal OF. Polyorganic insufficiency development in patients with liver cirrhosis with portal hypertension. Bulletin of Scientific Research. 2017. № 2. P. 88-92. 
5. Grjibovski AM, Ivanov SV, Gorbatova MA. Analysis of quantitative data in two independent samples using Statistica and SPSS software: parametric and non-parametric tests. Science \& Healthcare. 2016. № 2. P. 5-28.

6. Horalskyy LP, Khomych VT, Kononskyy OI. Fundamentals of histological technique and morphofunctional research methods in normal and in pathology. Zhytomyr: Polissya. 2011. 288 p.

7. Konovalenko SO. Morphometric analysis of structural changes in endothelial cells of arteries and veins of testes in the conditions at postresection portal hypertension. Art of Medicine. 2020. № 2 (14). P. 54-58.

8. Reddy SS, Civan JM. From Child-Pugh to model for end-stage liver disease: deciding who needs a liver transplant. Med. Clin. North Am. 2016. Vol. 100, Issue 3. P. 44964.

9. Tatarchuk LV, Hnatiuk MS. Morphometrical evaluation of peculiarities of structural reconstruction arteries of ileum at postresection portal hypertension. Achievements of Clinical and Experimental Medicine. 2018. № 2. P. 116-121.

10. Volchenko IV, Lyhman VN, Skoryi DI, Shevchenko AN. Features of the extensive liver resection, taking into account the prevention of postoperative complications. Kharkiv surgical school. 2016. № 3(78). P. 35-39. 